Polio Research Fund; and to Mrs. Dunnell and Miss Dales for their painstaking secretarial help.

\section{REFERENCES}

Bergstrand, C. G., Fahlén, T., and Thilén, A. (1957). Acta paediat. (Uppsala), 46, 10

Heycock, J. B., and Noble, T. C. (1964). Brit. med. f., 1, 658.

Muller, R., et al. (1958). Acta psychiat. Scand., Suppl. No. 126.

Nilsby, I. (1954). Acta paediat. (Uppsala), 43, Suppl. No. 95.

Nyhan, W. L., and Richardson, F. (1963). Ann. rev. Med., 14, 243.

Nyhan, W. L., and Richardson, F. (1963). Ann.
Wolff, O. (1952). Arch. Dis. Childh., 27, 302.

\section{Appendix A}

\section{Analysis of Initial Antibiotic Therapy in 64 Consecutive Cases of Bacterial Meningitis}

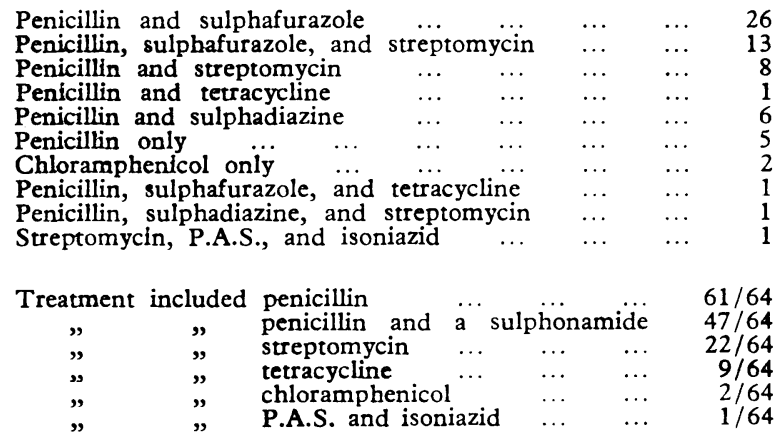

Initial treatment with one drug only

Penicillin $\quad \ldots \quad \ldots \quad 5$ cases ( 2 changed to chloramphenicol on second day. One died)

Chloramphenicol $\ldots \quad 2$ cases (both changed to other effective drugs in second week to avoid
toxicity)

\section{Intrathecal treatment}

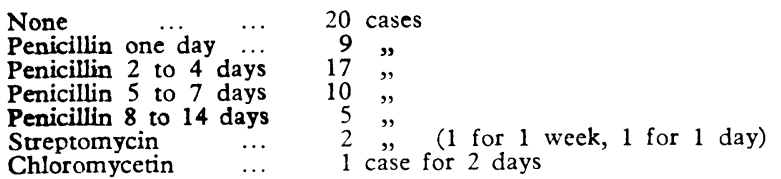

\section{Appendix B}

Analysis of Reasons for Changes Made in the Initial "Blind" Antibiotic Therapy

1. No change ... $\dddot{\ldots}$ was found either clinically or as a result No reason was found either clinically or as a result of sensitivity studies for change in the first blind choice
of single or combined antibiotic therapy. One patient died within six hours of admission before any treatment could become effective.

2. Withdrawal of an antibiotic

Antibiotic treatment changed solely by the withdrawal of an antibiotic subsequently shown to be ineffective by a sensitivity test from a group of otherwise effective a sensibiotics.

3. Toxicity

Change of antibiotics in view of toxicity or possible 38 cases toxicity. The change in each case was from one effective drug to another or by the withdrawal of a toxic member of an otherwise effective group.

4. Change of one agent as indicated by sensitivity tests Change of one member of a group only, the others being already effective.

5. Change of whole treatment as indicated by sensitivity tests Change of the single antibiotic or of the whole group none of which were effective as judged by sensitivity tests.

6. Change of antibiotic on clinical grounds ... ... $\ldots$ In all these cases cover was already adequate as either the addition of a further effective drug or the substitute of one "effective" drug for another.

Groups 1 to 6 total 65 cases, but one case was included twice.

In groups $1,2,3$, and 4 (a total of 54 cases, including 1 death) there was no reason, either clinically or bacteriologically, to think that the antibiotic cover was not fully effective throughout. In group 6, which contains seven cases, it is known that antibiotic cover was effective in all cases as shown by sensitivity tests, but changes were made in view of an apparently unsatisfactory initial clinical response.

There was no cause for any change on clinical grounds in any of the 12 cases in which we failed to culture an organism from the C.S.F. (usually because of previous treatment), although in Case 53 P.A.S. and isoniazid were stopped when initial doubts about the possibility of tuberculous meningitis were resolved.

Group 5, containing only three cases, is the only group in which it is known that initial therapy was probably ineffective. In all these cases, however, the change to effective antibiotic therapy, as judged by sensitivity tests, was made within the first two or three days after admission (in two cases chloramphenicol was substituted for penicillin, and in one case chloramphenicol for sulphafurazole).

\title{
Adrenal Function and the Inhibition of Allergic Responses Under Hypnosis
}

\author{
STEPHEN BLACK,* M.R.C.S., L.R.C.P.; MAX FRIEDMAN, $\dagger$ M.B., M.R.C.P.ED.
}

Possible psychophysiological mechanisms to explain the inhibition of allergic skin reactions by direct suggestion under hypnosis (D.S.U.H.) were reviewed in the British Medical Fournal (1964). As one possible explanation of these phenomena it was suggested that "tissue permeability can be altered by adrenocortical hormones, the secretion of which is controlled by the anterior pituitary and hence governed by the hypothalamus and all nervous mechanisms working thereon." Experimental investigation in this field, using hypnosis as a research tool (Black, 1963b), has demonstrated the production by D.S.U.H. of a shift in the dose-response curve of the Prausnitz-Küstner (P.K.) reaction. This technique of inves-

\footnotetext{
* Division of Human Physiology, Medical Research Council Laboratories, Hampstead, London.

† Medical Unit, University College Hospital, London.
}

tigation involves only the passive transfer of skin-sensitizing antibodies, so that effects due to hyposensitization can be eliminated and repeatable experimental conditions can be provided in the same subject. We have therefore investigated the role of adrenal function during the production of such a shift in the dose-response curve of the P.K. reaction by D.S.U.H.

Twelve experiments were performed on two female deeptrance hypnotic subjects defined as "deep-trance" according to the arbitrary classification of Black (1963a)-they were amnesic of the period of the hypnotic trance and could be psychologically regressed under hypnosis. The subjects had already responded to D.S.U.H. with a shift in the doseresponse curve of the P.K. reaction in previous experiments (Black, 1963b), and this was repeated in both subjects while estimations were made of the free plasma 11-hydroxycorticoids. 
In man, in contrast to the rat, the main free 11 hydroxycorticoid in plasma is cortisol (hydrocortisone), although corticosterone and aldosterone are also present in smaller amounts (Bush and Sandberg, 1953). In further experiments the effect of forceful D.S.U.H. of fear on the plasma-cortisol levels of one subject was also determined to assay the maximum levels of plasma cortisol which might be expected to occur as a result of hypnotic techniques in general. Adrenal function was then stimulated in both subjects by intravenous administration of adrenocorticotrophic hormone (A.C.T.H.) in appropriate dosage and the effects of such stimulation on the dose-response curve of the P.K. reaction were observed.

\section{Methods and Materials}

The dose-response curve of the P.K. reaction was estimated by techniques already described (Black, 1963b). The immediate skin response to horse serum was measured in terms of the weal areas resulting from the presence in the skin of passively transferred skin-sensitizing antibodies in an antihorse human serum, which had been previously inoculated intradermally at dilutions of $1 / 10,1 / 50,1 / 250,1 / 500$, and $1 / 1,000$. Such a response reaches its maximum between 15 and 40 minutes after pricking-in the horse serum, and it was therefore considered impracticable to assay adrenal function in terms of the urinary metabolites of adrenal steroids over this short period of time. Moreover, the alternative possibility of estimating adrenal function in terms of the eosinophil countwhich is known to fall on adrenal stimulation (Thorn, Forsham, Prunty, and Hills, 1948) - was also ruled out because of the numerous other factors known to influence the number of eosinophils in the blood (Acland and Gould, 1956).

The plasma cortisol was estimated by one of us (M.F.) by a modification of the fluorometric method described by Mattingly (1962). Plasma steroids were extracted into methylene chloride and fluorescence was induced by mixture with a fluorescence reagent consisting of 7 volumes of concentrated sulphuric acid and 3 volumes of ethyl alcohol. The fluorescence was read on a Locarte fluorimeter, using a zinc lamp as the exciting light in place of the mercury source employed by Mattingly. The primary filters used were Chance $\mathrm{OB} 10$ blue and Locarte LF3, which were found to provide greater specificity with excitation at 468, 472, and $481 \mathrm{~m} \mu$. The secondary filters used were Chance OG1 and OY3, which give a peak transmission around $540 \mathrm{~m} \mu$, while excluding light below $510 \mathrm{~m} \mu$.

There is a normal diurnal rhythm in the plasma-cortisol levels, which are highest between 08.00 and 09.00 hours and lowest at midnight, so that throughout the day a steady drop is recorded in normal individuals in good health (Mattingly, 1963). Our experiments were accordingly conducted over a standard period of time between 14.00 and 16.00 hours. To establish a baseline, from the onset of each experiment the subject rested supine on a couch in a quiet room with curtains drawn, and venous blood in $10-\mathrm{ml}$. volumes was taken at set intervals throughout the experimental period. These samples were taken at 14.00 hours and from then on after intervals of $30,60,75,90$, and 105 minutes.

To record the dose-response curve of the P.K. reaction the subject was prepared 24 hours previously at 15.00 hours by intradermal inoculation on the flexor surface of the forearm with freshly made-up dilutions of the anti-horse human serum as already described (Black, 1963b). On the day of the experiment the subject then rested on the couch from 14.00 hours onwards and blood samples were taken at the times stated. After the 60-minute sample-at 15.00 hours-drops of horse serum were placed on the inoculation sites and were then pricked-in. The horse serum was left in situ for one minute and then wiped off, and the resulting weal areas were recorded on Sellotape as described by Mason and Black (1958).
Such records were made at 15 and 30 minutes after prickingin the horse serum. The blood samples taken during this period at 75 and 90 minutes were obtained by venepuncture and from the other arm immediately before the weal-area records were made.

Not less than 14 days later the experiment was then repeated on the opposite arm. On this occasion, however, the subject was hypnotized before pricking-in the horse serum and, as already described, D.S.U.H. was given that there would be no response (Black, 1963b). In the case of subject I, D.S.U.H. was given as post-hypnotic suggestion and the subject was awakened before proceeding further with the experiment. In the case of subject II, D.S.U.H. was given and reinforced at intervals for 45 minutes, so that the subject remained hypnotized throughout the rest of the experiment. In both instances records of the weal areas, if present, were made as before at 15 and 30 minutes after pricking-in horse serum and blood samples were again taken by venepuncture from the other arm.

Before proceeding to the second part of the experiment, which involved estimating the effects on the P.K. reaction of intravenous administration of A.C.T.H., it was necessary to assay the physiological levels of plasma cortisol which might be expected to occur as a result of D.S.U.H. This was carried out on subject II and a baseline recorded in the usual way for the first 60 minutes. Forceful D.S.U.H. of fear was then given fairly continuously over a period of 45 minutes tc produce the maximum subjective response possible. The words used were : "You are frightened ... you feel frightened ... you are frightened of something . . . you are frightened." Objectively the subject reacted to these suggestions with increased heart rate, increased respiration rate, sweating hands, and weeping and wringing of the hands. Subjectively, she declared herself frightened of a variety of images, some of which were regressive and some of which related to her current life as a mother and housewife.

The 60-minute blood sample was taken before D.S.U.H. was given and the other samples at 75, 90, and 105 minutes. At this point in time (15.45 hours) the suggestions of fear were cleared, the subject was calmed and relaxed under hypnosis and then awakened. A single further blood sample was then taken an hour later, at 165 minutes (16.45 hours).

A psychophysiological variation in the plasma-cortisol levels having been determined in this way, the adrenal function of subject I was then titrated with A.C.T.H. in an intravenous dextrose-saline drip, so as to estimate the amount of A.C.T.H. required to produce variations in the plasma-cortisol levels of the same order as those produced by D.S.U.H. of fear. The second part of the experiment was then carried out on both subjects.

The dose-response curve of the P.K. reaction was first elicited in the waking state on one arm, but in the presence of an intravenous drip of $4.3 \%$ dextrose and $0.9 \%$ saline, which was started at the outset of the experimental period of 14.00 hours. This was then repeated on the other arm, but after the usual resting blood samples had been taken the drip-bottle was changed to deliver 9 international units (I.U.) of crystalline A.C.T.H. over 45 minutes in the same dextrose-saline medium. With subject II each arm was tested separately at an interval of 14 days and records of the weal areas were made on both occasions 15 minutes after pricking-in the horse serum. With subject I both arms were prepared simultaneously and were tested the next day within 45 minutes of one another. The A.C.T.H. drip on this occasion was started 15 minutes prior to prickingin the horse serum on the second arm and on both arms the weal areas were recorded 30 minutes after pricking-in the horse serum.

\section{Results}

The resting plasma-cortisol levels of both subjects over the experimental period from 14.00 hours onwards are shown in 
Fig. 1. In Table I the falls in cortisol levels at rest are compared with the cortisol levels as recorded during the production of a P.K. reaction and during a shift in the dose-response curve of the P.K. reaction by D.S.U.H. in each subject.

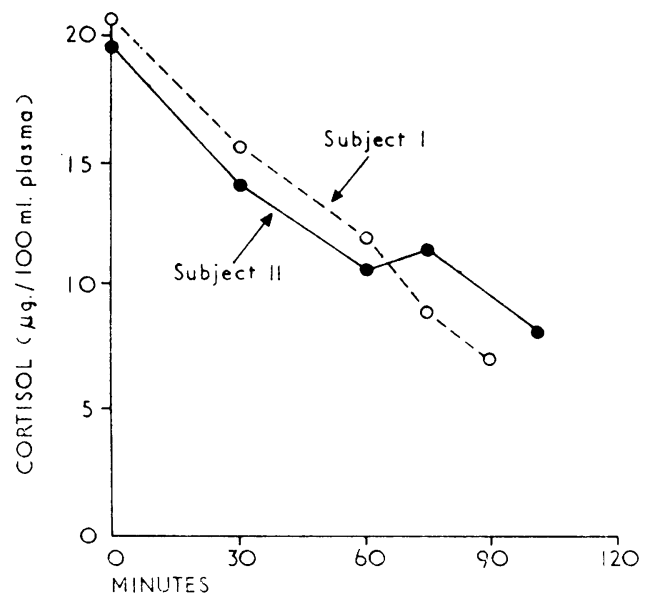

FIG. 1.-Changes in plasma-cortisol levels at rest over experimental period $14.00-16.00$ hours.

Table I.-Variations in Plasma-cortisol Levels During a Shift in the Dose-response Curve of the P.K. Reaction by D.S.U.H.

\begin{tabular}{|c|c|c|c|c|c|c|c|}
\hline \multirow{3}{*}{$\begin{array}{l}\text { Time } \\
\text { of } \\
\text { Day }\end{array}$} & \multirow{3}{*}{$\begin{array}{l}\text { Mins. } \\
\text { of } \\
\text { Exp. }\end{array}$} & \multicolumn{6}{|c|}{$\mu \mathrm{g}$. Cortisol per $100 \mathrm{ml}$. Plasma } \\
\hline & & \multicolumn{3}{|c|}{ Subject I } & \multicolumn{3}{|c|}{ Subject II } \\
\hline & & $\begin{array}{l}\text { Normal } \\
\text { Diurnal } \\
\text { Change }\end{array}$ & $\begin{array}{l}\text { Change } \\
\text { During } \\
\text { P.K. } \\
\text { Reaction }\end{array}$ & $\begin{array}{c}\text { During } \\
\text { P.K. } \\
\text { Reaction } \\
\text { Inhibition }\end{array}$ & $\begin{array}{l}\text { Normal } \\
\text { Diurnal } \\
\text { Change }\end{array}$ & $\begin{array}{c}\text { Change } \\
\text { During } \\
\text { P.K. } \\
\text { Reaction }\end{array}$ & $\begin{array}{l}\text { During } \\
\text { P.K. } \\
\text { Reaction } \\
\text { Inhibition }\end{array}$ \\
\hline 14.00 & 0 & $20 \cdot 4$ & $16 \cdot 8$ & $18 \cdot 6$ & $19 \cdot 4$ & $20 \cdot 0$ & $13 \cdot 0$ \\
\hline 15.00 & $\begin{array}{l}30 \\
60\end{array}$ & $\begin{array}{l}15.6 \\
11 \cdot 8\end{array}$ & $\begin{array}{l}15 \cdot 6 \\
12 \cdot 4\end{array}$ & $\begin{array}{l}13 \cdot 8 \\
17 \cdot 2\end{array}$ & $\begin{array}{l}14 \cdot 0 \\
10 \cdot 6\end{array}$ & $\begin{array}{l}16 \cdot 4 \\
12 \cdot 2\end{array}$ & $\begin{array}{r}13 \cdot 0 \\
9 \cdot 2\end{array}$ \\
\hline & 75 & 8.8 & 10.9 & 9.4 & 11.3 & 10.8 & $11 \cdot 8$ \\
\hline & 90 & $7 \cdot 0$ & $9 \cdot 6$ & $8 \cdot 2$ & $8 \cdot 2$ & $10 \cdot 4$ & $11 \cdot 6$ \\
\hline \multirow{2}{*}{16.00} & 105 & 一 & $9 \cdot 0$ & $7 \cdot 6$ & - & $8 \cdot 6$ & $12 \cdot 2$ \\
\hline & $\begin{array}{l}120 \\
165\end{array}$ & - & 二 & 二 & $\overline{7 \cdot 2}$ & 二 & - \\
\hline
\end{tabular}

Fig. 2 is a diagram which displays the response of subject I when a shift in the P.K. reaction dose-response curve was produced by D.S.U.H. using post-hypnotic suggestion. The height of each column records the P.K.-reaction weal area in sq. $\mathrm{mm}$. as measured at 15 minutes for each dilution of skinsensitizing serum inoculated. It will be seen that the response

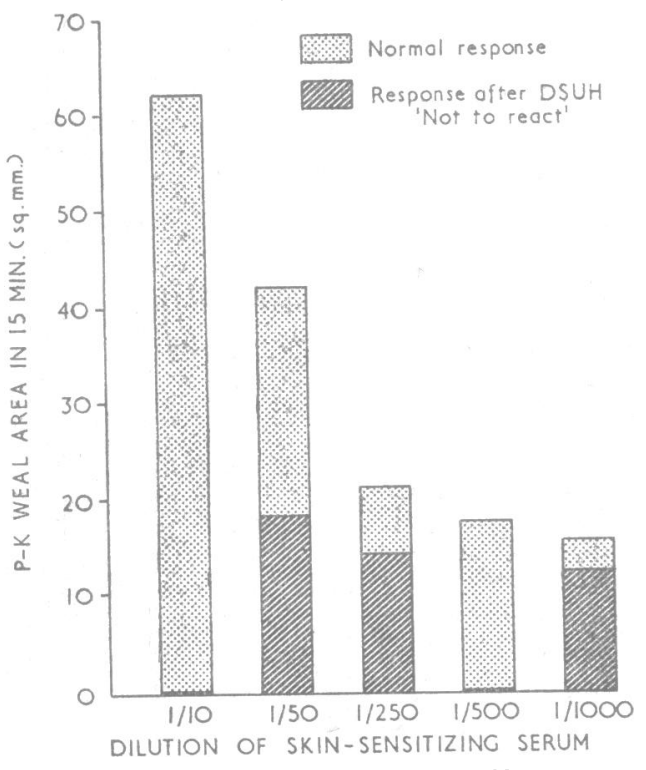

Fig. 2.-Subject I. Effect of D.S.U.H. "nat to react" on P.K. reaction, by post-hypnotic suggestion. to a dilution of $1 / 10$ was reduced from a weal area of $62 \mathrm{sq}$ $\mathrm{mm}$. to zero and that a similar reduction to zero occurred at a dilution of $1 / 500$. Reductions were also recorded at $1 / 50$, $1 / 250$, and $1 / 1,000$. In general, clear-cut evidence of a shift in the dose-response curve was shown.

Fig. 3 records the plasma-cortisol levels during the normal P.K. reaction and the levels when the shift in the dose-response curve was produced by D.S.U.H. as shown in Fig. 2. Following D.S.U.H. " not to react" there was a continued drop as in the control, although a rise was recorded between 30 and 60 minutes before D.S.U.H. was given.

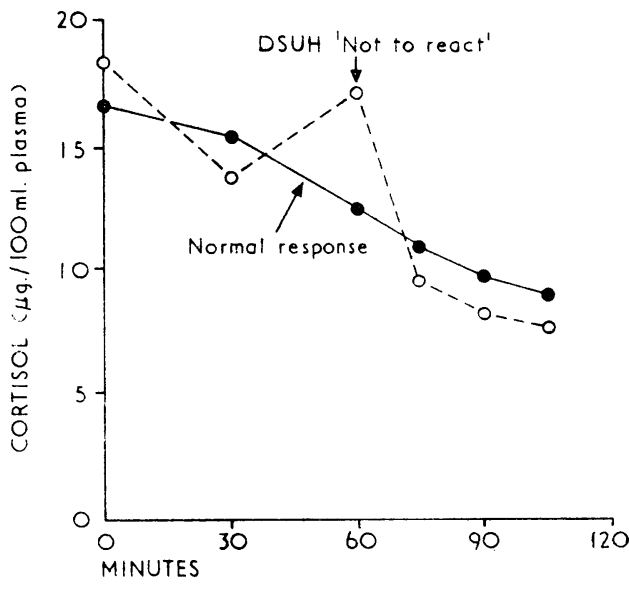

FIg. 3.-Subject I. Plasma-cortisol levels during inhibition of P.K. reaction by D.S.U.H. by posthypnotic suggestion.

Fig. 4 displays in the same way the response obtained in subject II, when a more pronounced shift in the dose-response curve of the P.K. reaction was produced by D.S.U.H. " not to react" with reinforcement under continued hypnosis for 45 minutes. The weal area at the serum dilution of $1 / 10$ was reduced from 31 to $17 \mathrm{sq}$. $\mathrm{mm}$. and to zero at all other dilutions. The weal areas shown were measured at 30 minutes after pricking-in horse serum.

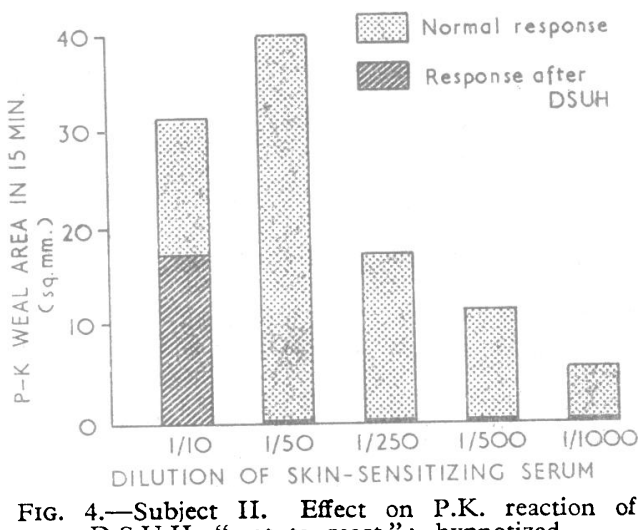

Fig. 5 records the plasma-cortisol levels during this shift in the dose-response curve in subject II, as recorded in Fig. 4. On this occasion a slight rise of some $3 \mathrm{~g}$. of cortisol per 100 ml. of plasma was recorded after D.S.U.H. " not to react" was given, but is hardly significant.

The effect on the dose-response curve of the P.K. reaction of a rise in the plasma-cortisol levels was then investigated without the use of hypnosis. However, it was first necessary to determine the order of psychophysiological variation in the plasma-cortisol levels which might be produced by hypnotic techniques. Fig. 6 shows the variation in the plasma-cortisol levels of subject II when forceful D.S.U.H. of fear was given 
and reinforced for 45 minutes. It will be seen that a rise of $13.4 \mathrm{~g}$. of cortisol per $100 \mathrm{ml}$. of plasma was recorded. After the suggestions were cleared and the subject was calmed and awakened, the fall rate in the plasma-cortisol level was relatively slow, and after one hour had dropped by only $8 \mu \mathrm{g}$. Titration of subject I with A.C.T.H. by intravenous drip in a glucose-saline medium then indicated that administration of 9 I.U. of crystalline A.C.T.H. over a period of 45 minutes produced a rise in the plasma-cortisol level of the same order as that recorded in response to D.S.U.H. of fear in subject II.

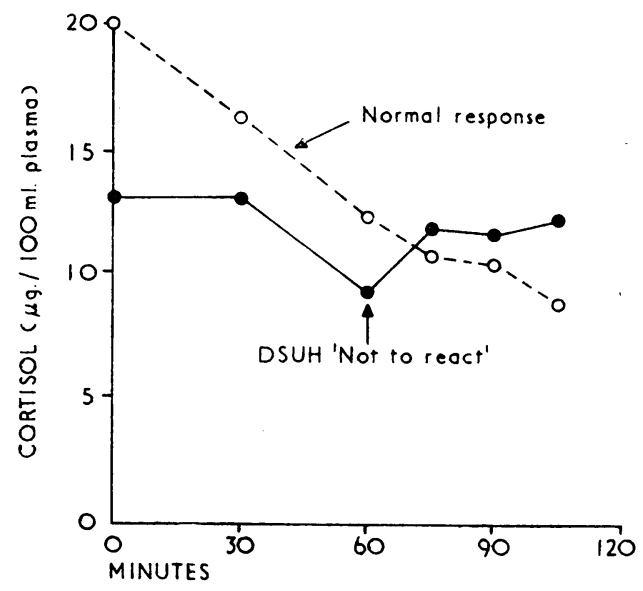

FIG. 5.-Subject II. Plasma-cortisol levels during inhibition of P.K. reaction by D.S.U.H. : hypnotized.

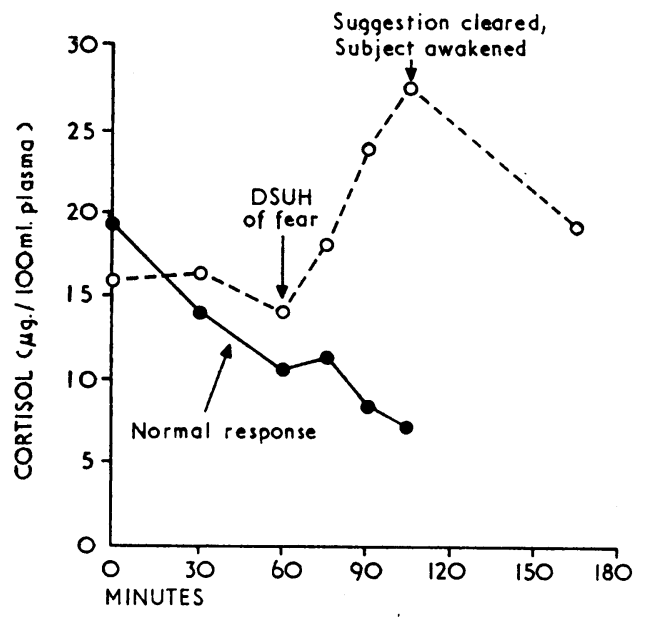

FIG. 6.-Subject II. Plasma-cortisol levels during D.S.U.H. of fear.

The weal areas for the different dilutions of skin-sensitizing serum as recorded on both subjects in this part of the experiment are shown in Table II. From these figures it can be seen that the normal response and the response during ıdministration of A.C.T.H. by intravenous drip are very similar to one another in both subjects.

[ABLE II.-Effect of Intravenous A.C.T.H. on the Dose-response Curve

\begin{tabular}{|c|c|c|c|c|}
\hline \multirow{2}{*}{$\begin{array}{l}\text { Dilution } \\
\text { of Skin- } \\
\text { sensitizing } \\
\text { Serum }\end{array}$} & \multicolumn{2}{|c|}{$\begin{array}{l}\text { Subject II } \\
\text { P.K.-reaction Weal Areas at } \\
15 \text { mins. in sq. mm. }\end{array}$} & \multicolumn{2}{|c|}{$\begin{array}{l}\text { Subject I } \\
\begin{array}{c}\text { P.K. -reaction Weal Areas at } \\
30 \text { mins. in sq. } \mathrm{mm} \text {. }\end{array} \\
\end{array}$} \\
\hline & $\begin{array}{l}\text { Normal } \\
\text { Response } \\
\text { Left Arm }\end{array}$ & $\begin{array}{l}\text { Sesponse on } \\
\text { A.C.T.H. Drip } \\
\text { Right Arm: } \\
9 \text { I.U. } / 45 \text { mins. } \\
\end{array}$ & $\begin{array}{l}\text { Normal } \\
\text { Response } \\
\text { Left Arm }\end{array}$ & $\begin{array}{l}\text { Response on } \\
\text { A.C.T.H. Drip } \\
\text { Right Arm: } \\
9 \text { I.U. } / 45 \text { mins. }\end{array}$ \\
\hline $\begin{array}{l}1 / 10 \\
1 / 50 \\
1 / 250 \\
1 / 500 \\
1 / 1,000\end{array}$ & $\begin{array}{r}52 \\
32 \\
16 \\
10 \\
5\end{array}$ & $\begin{array}{r}56 \\
28 \\
18 \\
11 \\
6\end{array}$ & $\begin{array}{l}42 \\
47 \\
32 \\
26 \\
21\end{array}$ & $\begin{array}{l}64 \\
59 \\
30 \\
28 \\
21\end{array}$ \\
\hline
\end{tabular}

These results are displayed in Figs. 7-10. Fig. 7 shows the dose-response curves for subject II where dilution of skinsensitizing serum is plotted $\log -\log$ against weal area in sq. $\mathrm{mm} . \times 10$. The normal response on the left arm is compared with the response on the right arm in the presence of an A.C.T.H. drip which was started synchronously with the pricking-in of horse serum. Both sets of weal-area records were made 15 minutes after the horse serum was pricked-in. Fig. 8 shows the effect on the plasma-cortisol levels of the intravenous A.C.T.H. drip in this experiment. Comparing both figures, it can be seen that, although the plasma-cortisol level rose at the rate of $18.8 \mu \mathrm{g}$. per $100 \mathrm{ml}$. of plasma in 45 minutes, there was no shift in the dose-response curve of the P.K. reaction. This is confirmed by a statistical test of the difference of the two slopes which shows that there is no significant difference.

Fig. 9 shows the two dose-response curves for subject I, when both arms were prepared synchronously and horse serum was pricked-in to the right arm within 45 minutes of

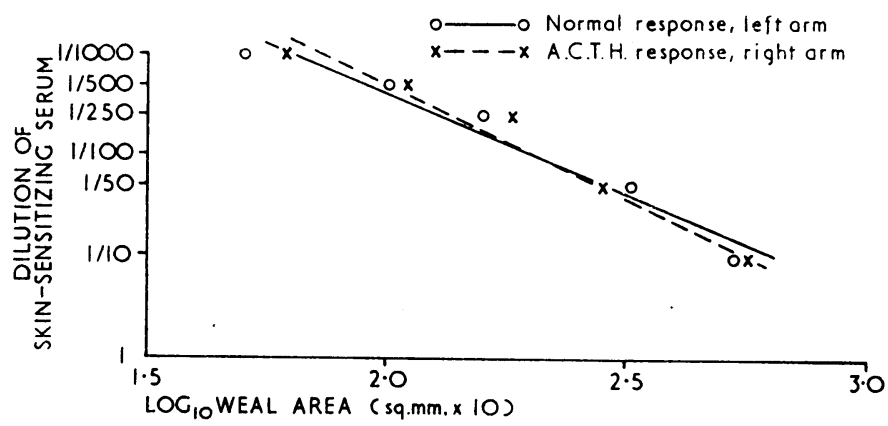

PIG. 7.-Subject II. Effect of intravenous A.C.T.H. on dose-response curve of P.K. reaction, at 15 minutes.

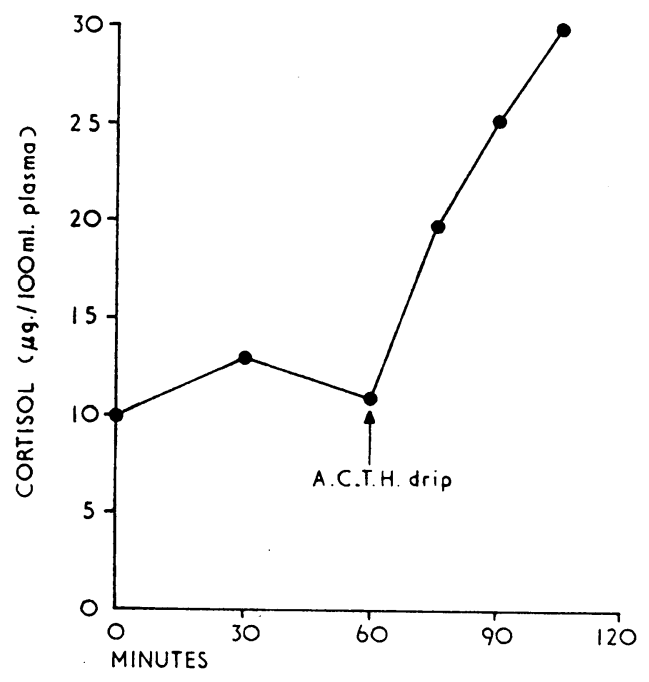

FIG. 8.- Subject II. Effect on plasma-cortisol levels of intravenous A.C.T.H. drip as in Fig. 7.

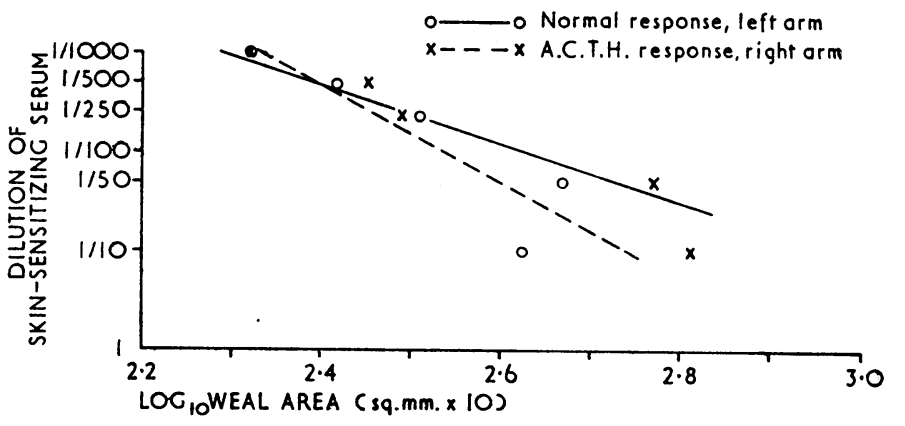

FIG. 9.-Subject I. Effect of intravenous A.C.T.H. on dose-response curve of P.K. reaction, at 30 minutes.

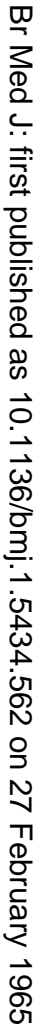

(1)


the left. The normal response on the left arm as recorded at 30 minutes is very similar to the 30 -minute response on the right arm after the A.C.T.H. drip had been running 45 minutes and the full dose of 9 I.U. of A.C.T.H. had been administered. Fig. 10 shows the effect on the plasma-cortisol levels of the A.C.T.H. drip which produced a rise of $26 \mu \mathrm{g}$. of cortisol per $100 \mathrm{ml}$. of plasma in the 45 minutes before the weal-area records from the right arm were made as in Fig. 9. Comparing both figures, it can be seen that no shift in the dose-response curve of the P.K. reaction was produced, in spite of this marked rise in the plasma-cortisol level. The absence of any shift is again confirmed statistically.

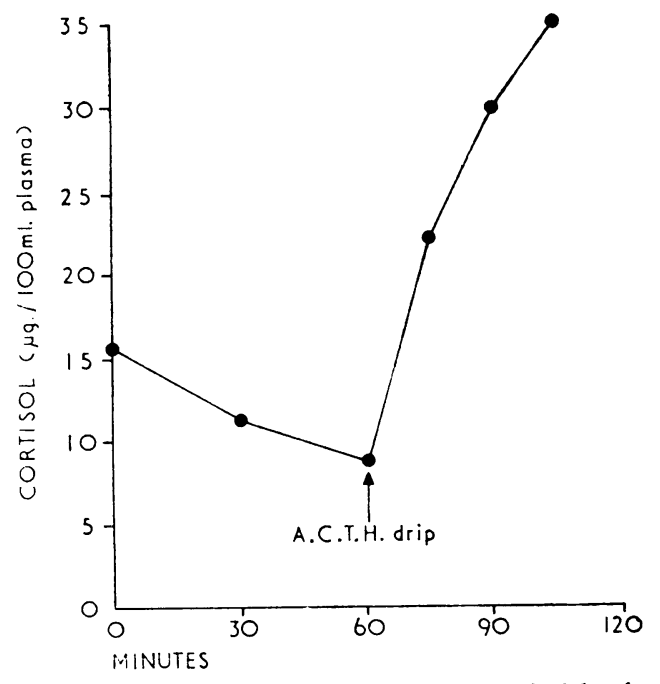

FIG. 10.-Subject I. Effect on plasma-cortisol levels of intravenous A.C.T.H. drip as in Fig. 9.

\section{Discussion}

A good source of information on the effects of stress on adrenal function is the monograph by Thomasson (1959), which reviews the literature and presents his findings in a series of normal subjects and surgical patients. Clearly there is already much evidence that variations in the plasma-corticosteroid levels occur as a result of stress situations in general. The hypothesis that such changes might play some part in the inhibition of allergic responses by suggestion therefore seemed likely. However, the results of our experiments reported here indicate that a shift in the dose-response curve of the P.K. reaction by D.S.U.H. can be brought about without any significant change in the plasma-cortisol levels. Moreover, the subsequent intravenous administration of A.C.T.H. during the production of a P.K. reaction would appear to have clinched the matter. The intravenous administration of 9 I.U. of A.C.T.H. over 45 minutes in a glucose-saline medium produced a rise in plasma cortisol of the same order as that recorded when forceful D.S.U.H. of fear was given-yet there was no shift in the dose-response curve of the P.K. reaction in either subject.

The problem of the nature of the psychophysiology involved in the inhibition of such allergic skin reactions by suggestion therefore still remains unsolved. The British Medical fournal (1964) raised, in addition, the question of whether such effects might be produced by neurovascular mechanisms, and cited the work of Rosenblueth and Cannon (1934) because of their conclusion that antidromic impulses in afferent nerves were responsible for peripheral vasodilatation observed in emotionally disturbed dogs - an effect which was also produced by electrical stimulation of the medulla. However, Black, Edholm, Fox, and Kidd (1963a) showed that when D.S.U.H. of thermal stimuli was given no significant variation was produced in forearm and hand blood-flow. In general, this work and that of Doupe, Miller, and Keller (1939), suggests that neurovascular mechanisms are unlikely to play any part in the inhibition by D.S.U.H. of the P.K. reaction as in our experiments, or in the inhibition by D.S.U.H. of the immediate-type hypersensitivity response (Black, 1963a), or the inhibition by D.S.U.H. of local oedema in the delayed-type hypersensitivity response as typified by the Mantoux reaction (Black, Humphrey, and Niven, 1963b).

The blood-flow studies of Black et al. (1963a) emphasized the importance of distinguishing between (1) hypnosis per se, (2) direct suggestion under hypnosis, and (3) indirect suggestion under hypnosis when using hypnosis as a research tool in the study of psychophysiological mechanisms. Neither hypnosis per se nor the direct suggestion "You are hot" produced any significant change in the haemodynamic picture. However, the indirect suggestion "You are hot because the house is on fire" produced forearm and hand blood-flow changes similar to those observed in cases of anxiety by Blair, Glover, Greenfield, and Roddie (1959) and Barcroft, Brod, Hejl, Hirsjärvi, and Kitchin (1960). Moreover, Black and Wigan (1961), working in acoustics, demonstrated that variations in the physiological response could result from semantic differences in the hypnotic suggestion, as has now been confirmed by Arwyn Evans (1965), investigating the use of hypnosis in obstetrics.

In general, the use of hypnosis as a research tool in both allergy and neurophysiology has shown the extreme delicacy of the informational mechanisms involved. In their work on the expectancy waves in anterior cortex Black and Walter (1965) demonstrated that even an implied suggestion could produce its effects. Such implied suggestion is possibly the explanation of the relative inhibition of the immediate-type hypersensitivity response by hypnosis per se in cases of atopic asthma as reported by Fry, Mason, and Pearson (1964). In our experiments, for example, it will be noted that when D.S.U.H. of fear was given to assay the psychophysiological variations in the plasma-cortisol levels as produced by hypnotic techniques, although the suggestion "You are frightened ..." was technically " direct," the subject's report of her experience implied " indirect" features to which her fears were spontaneously related.

However, unlike variations in blood-flow and apparently in adrenal function also, inhibition of allergic responses can be brought about by "direct" suggestion alone-a fact now firmly established, both clinically (Mason and Black, 1958) and experimentally (Black, 1963a, 1963b; Black et al., 1963b). Inhibition as a result of such suggestion is usually immediate (instant inhibition), but it may be delayed, suggesting the build-up of a humoral factor. That the effects of suggestion under hypnosis appear to be a function of the depth of trance of the subject indicates perhaps that emotional tone plays some part.

In considering other mechanisms in the psychophysiological inhibition of allergy it should be recognized that the elimination of cortisol and the stimulation of adrenal function by A.C.T.H. does not rule out the possibility of pituitaryadrenal mechanisms not yet open to investigation.

\section{Conclusions}

It is concluded that a shift in the dose-response curve of the P.K. reaction produced by direct suggestion under hypnosis does not involve stimulation of adrenal function by the hypothalamic-pituitary-adrenal axis to produce a rise in the plasma-cortisol levels, measured as free plasma 11-hydroxycorticoids. Moreover, it seems most unlikely that a shift in the dose-response curve of the P.K. reaction is produced by mechanisms which differ greatly from those involved in inhibition by direct suggestion under hypnosis of the immediate-type hypersensitivity response, or the inhibition of local oedema in the delayed-type hypersensitivity response as 
typified by the Mantoux reaction. It is therefore further concluded that, in general, inhibition of all allergic reactions by direct suggestion under hypnosis is very unlikely to involve any rise in the plasma cortisol levels due to central stimulation of adrenal function.

\section{Summary}

The plasma cortisol levels were estimated in two deeptrance hypnotic subjects during production of a shift in the dose-response curve of the Prausnitz-Küstner reaction by direct suggestion under hypnosis. The results showed that no significant change of the plasma cortisol levels occurred during such a shift in the curve. Moreover, there was no shift in the curve when a rise in plasma cortisol occurred as a result of adrenal stimulation by adrenocorticotrophic hormone in dosage established as being within the psychophysiological limits.

It is concluded that a shift in the dose-response curve of the Prausnitz-Küstner reaction by direct suggestion under hypnosis does not involve stimulation of adrenal function by the hypothalamic-pituitary-adrenal axis to produce a rise in the plasma cortisol levels. It is further concluded that cortisol is unlikely to play any part in the inhibition by direct suggestion under hypnosis of allergic skin reactions in general.

Our thanks are due to the Medical Research Council, Ergonomics Limited, the Parapsychology Foundation of New York, and the Nuffield Foundation for financial assistance. Our thanks are also due to Dr. O. G. Edholm for the technical assistance provided by the Division of Human Physiology of the Medical Research Council, and to Dr. J. H. Humphrey, of the National Institute for Medical Research, Mill Hill, for supplying the "hepatitis-free" skinsensitizing human serum used throughout in the production of the Prausnitz-Küstner reaction. We would also like to thank $\mathrm{Mr}$ Martin Whittiker, of the Medical Research Council Laboratories, London, for his statistical tests of the significance of our results.

\section{REFERENCES}

Acland, J. D., and Gold, A. H. (1956). F. Physiol. (Lond.), 133, 456. Barcroft, H., Brod, J., Hejl, Z., Hirsjärvi, E. A., and Kitchin, A. H. (1960). Clin. Sci., 19, 577 .

Black, S. (1963a). Brit. med. F., 1, 925.

- (1963b). Ibid., 1, 990

Edholm, O. G., Fox, R. H., and Kidd, D. J. (1963a). Clin. Sci.

25, 223, O. G., Fox, R. H., and Kidd, D. J. (1963a). Clin. Sci., Hum 1649

and Walter, W. Grey (1965). 7. Psychosom. Res. In press.

and Wigan, E. R. (1961). Brit. med. F., 2, 736.

Blair, D. A., Glover, W. E., Greenfield, A. D. M., and Roddie, I. C. (1959). '7. Physiol. (Lond.), 148, 633.

Brit. med. F., 1964, 1, 1129.

Bush, I. E., and Sandberg, A. A. (1953). 7. biol. Chem., 205, 783.

Doupe, J., Miller, W. R., and Keller, W. K. (1939). F. Neurol. Psychiat. 2, 97 .

Evans, Arwyn (1965). Personal communication.

Fry, L., Mason, A. A., and Pearson, R. S. B. (1964). Brit. med. 7., 1 1145.

Mason, A. A., and Black, S. (1958). Lancet, 1, 877.

Mattingly, D.' (1962). 7. clin. Path., 15, 374.

- (1963). Proc. roy. Soc. Med., 56, 717.

Rosenblueth, A., and Cannon, W. B. (1934). Amer. F. Physiol., 108, 599.

Thomasson, B. (1959). Scand. F. clin. Lab. Invest., 11, Suppl. No. 42.

Thorn, G. W., Forsham, P. H., Prunty, F. T. G., and Hills, A. G. (1948). F. Amer. med. Ass., 137, 1005.

\section{Medical Memoranda}

\section{Acute Renal Failure Complicating Lymphosarcoma}

\section{Brit. med.f., 1965, 1, 567-568}

Several reports of acute renal failure complicating reticulosis have appeared in recent years (Merrill, 1940; Merrill and Jackson, 1943 ; Kravitz et al., 1951 ; Kritzler, 1958 ; Greenbaum and Hope Stone, 1959 ; Duncan et al., 1963). Disease infiltration of the kidney, amyloidosis, or hyperuricaemia may be responsible. Hyperuricaemia occurs in untreated reticulosis (Sandberg et al., 1956), but is increased by radiotherapy (Lennox and Means, 1923), cytotoxins, and corticosteroids. Urate precipitation may then obstruct the renal tract. Successful treatment by haemodialysis has been reported (Firmat et al., 1960 ; Duncan et al., 1963).

A patient with lymphosarcoma developed renal failure on two occasions ; the first was due to hyperuricaemia following radiotherapy, and the second, four months later, was produced by extensive infiltration of both kidneys by lymphosarcoma. It is noteworthy that severe hyperuricaemia followed a small dose of radiotherapy.

\section{CAse Report}

A 47-year-old man developed a painful swelling in his right groin in mid-February 1963. Biopsy at a hospital in France was unsatisfactory and he was admitted to R.A.F. Hospital, Wegberg, where axillary, right cervical, and right inguinal glands were found to be enlarged. Biopsy of a right cervical gland showed lymphosarcoma.

He was admitted to R.A.F. Hospital, Uxbridge, on $25 \mathrm{March}$, and between 17 April and 20 May was treated at Westminster Hospital by radiotherapy to the right groin $(5,000 \mathrm{r}$ ) and to both axillae $(4,000 \mathrm{r})$. The masses regressed rapidly and he was discharged from hospital on 23 May. In early July he developed listlessness, anorexia, and progressive abdominal distension. He was readmitted to Uxbridge on 2 August, when marked abdominal swelling due to ascites, para-aortic glandular masses, and hepatomegaly was found.

Between 8 and 13 August he received $500 \mathrm{r}(100 \mathrm{r}$ daily $\times 5)$ to the whole abdomen ( 36 sq. cm.) at Mount Vernon Hospital. On 11 August remarkable regression of the abdominal glands was noted, but he had considerable nausea and severe abdominal pain. On 13 August he had an epileptiform convulsion and complained of blurred vision and severe lower abdominal pain.

His symptoms persisted next day, when a 24-hour urine output of $360 \mathrm{ml}$. was noted. On 15 August renal failure was diagnosed; serum uric acid was $45 \mathrm{mg} . / 100 \mathrm{ml}$., blood urea $203 \mathrm{mg} . / 100 \mathrm{ml}$., and serum potassium $6.8 \mathrm{mEq} / 1$. Conservative treatment was instigated and on 16 August his condition had improved, but serum uric acid was $42.5 \mathrm{mg} . / 100 \mathrm{ml}$., blood urea $214 \mathrm{mg} . / 100 \mathrm{ml}$., serum potassium $6.5 \mathrm{mEq} / 1$; ; 30 -hour urine volume was $275 \mathrm{ml}$., S.G. 1011. At this stage he was transferred to the Renal Unit, Princess Mary's R.A.F. Hospital, Halton.

On admission he was uraemic and overhydrated, and urine deposit showed many uric acid crystals. The next morning (17 August) serum uric acid was $34 \mathrm{mg} . / 100 \mathrm{ml}$., plasma urea $475 \mathrm{mg} . / 100 \mathrm{ml}$., and potassium $7 \mathrm{mEq} / 1$. He was dialysed for six hours, using a Kolff twin-coil artificial kidney. Blood uric acid and urea, and urine volumes, are shown in the Chart. He produced $100 \mathrm{ml}$. of urine 